\begin{tabular}{|l|l|}
\hline SEP 261997,39 ENGINEERING DATA TRANSMITTAL & Page 1 of 1 \\
\hline Sta. 37 & 1. EDT 618914 \\
\hline
\end{tabular}

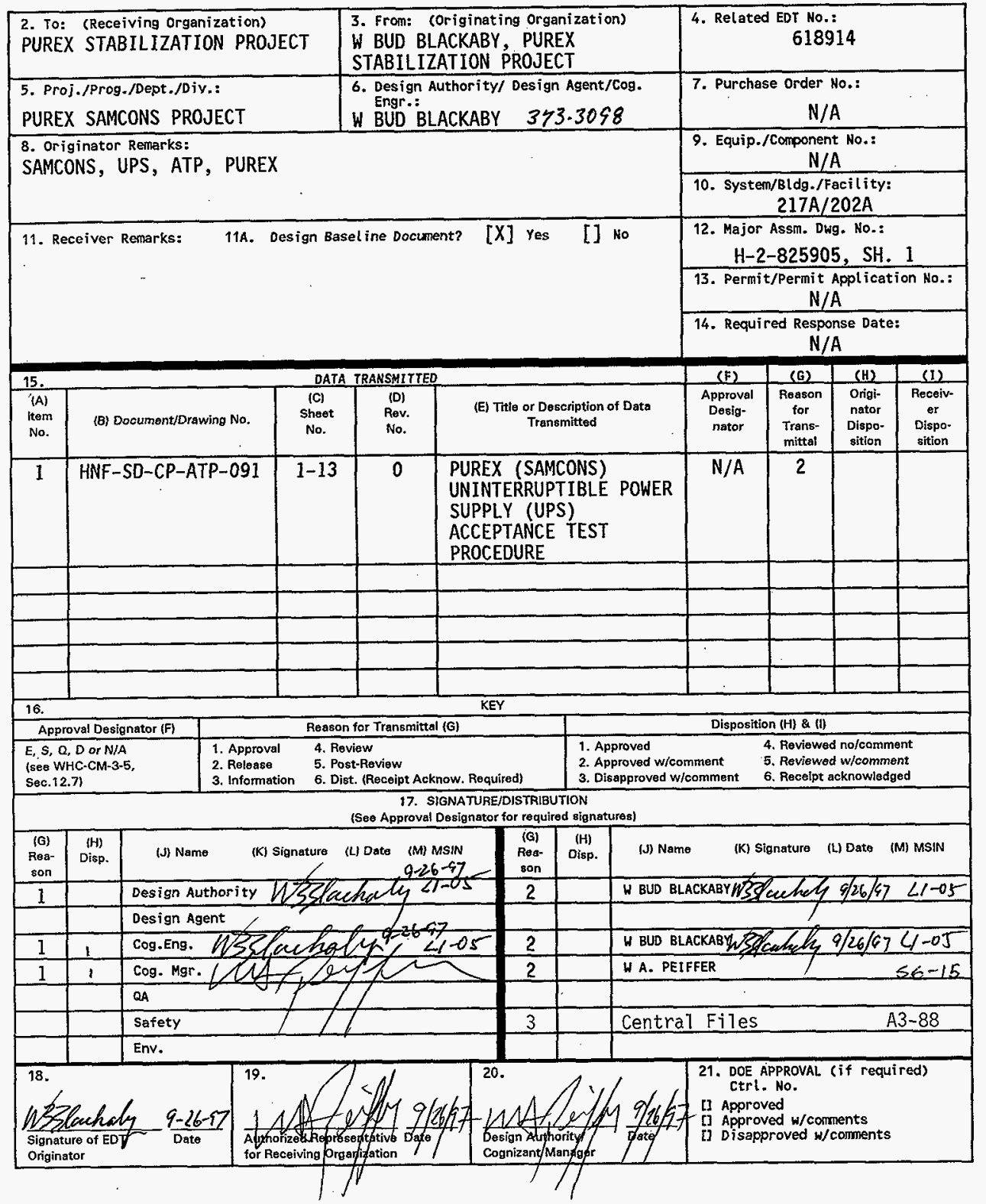




\title{
PUREX (SAMCONS) UNINTERRUPTIBLE POWER SUPPLY (UPS) ACCEPTANCE TEST PROCEDURE
}

\author{
W BUD BLACKABY \\ BWHC, Richland, WA 99352 \\ U.S. Department of Energy Contract DE-AC06-96RL.13200 \\ EDT/ECN: $\quad 618914$ \\ UC: 506 \\ Org Code: 17320 \\ Charge Code: KP4BA \\ B\&R Code: 1 MBF530403 7050000 Tota1 Pages: -13- 14 \\ Key Words: SAMCONS, UPS, ATP, PUREX
}

Abstract: This Acceptance Test Procedure for the PUREX Surveillance and Monitoring and Control System (SAMCONS) Uninterruptible Power Supply (UPS) provides for testing and verifying the proper operation of the control panel alarms and trouble functions, the proper functioning of the AC inverter, ability of the battery supply to maintain the SAMCONS load for a minimum of two hours, and proper interaction with the SAMCONS Video graphic displays for alarm displays.

TRADEMARK DISCLAIMER. Reference herein to any specific commercial product, process, or service by trade name, trademark, manufacturer, or otherwise, does not necessarily constitute or imply its endorsement, recommendation, or favoring by the United states Goverment or any agency thereof or its contractors or subcontractors.

Printed in the United states of America. To obtain copies of this document, contact: Document Control Services, P.O. BOX 950, Mailstop H6-08, Richland WA 99352, Phone (509) 372-2420; Fax (509) 376-4989.
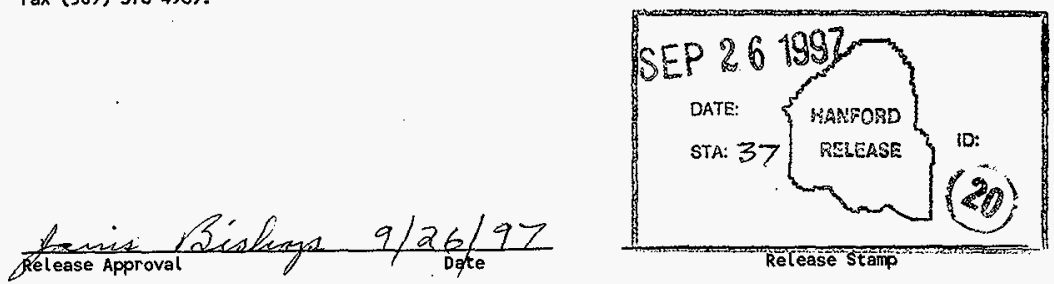


\section{PUREX (SAMCONS) UNINTERRUPTIBLE POWER SUPPLY (UPS) ACCEPTANCE TEST PROCEDURE}

\section{HNF-SD-CP-ATP-091 REVISION 0}

Prepared by: W, "Bud" Blackaby

September 1997 


\section{TABLE OF CONTENTS}

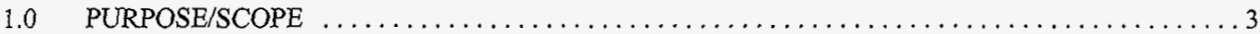

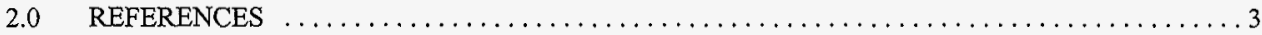

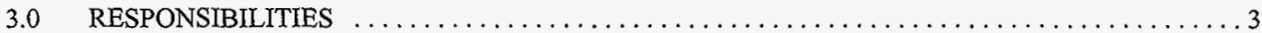

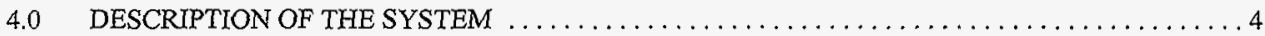

5.0 TEST CONDITIONS AND EQUIPMENT REQUIRED $\ldots \ldots \ldots \ldots \ldots \ldots \ldots \ldots \ldots \ldots \ldots$

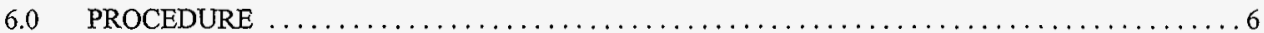

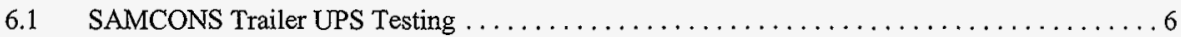

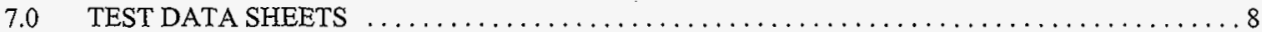

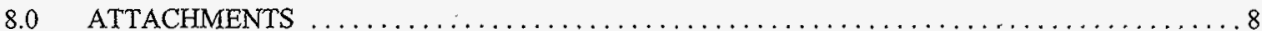

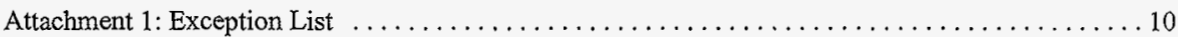

Attachment 2: Measurement and Test Equipment Record Sheet $\ldots \ldots \ldots \ldots \ldots \ldots \ldots \ldots \ldots \ldots \ldots \ldots$

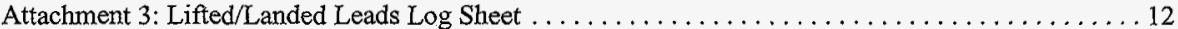

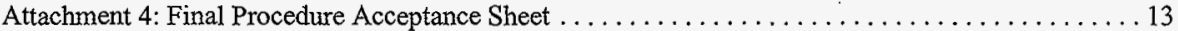

DOCUMENT NO:

HNF-SD-CP-ATP-091
REVISION NO:

0
PAGE NO:

2 OF 13 


\section{PUREX (SAMCONS) UPS ACCEPTANCE TEST PROCEDURE}

\subsection{PURPOSE/SCOPE}

The proper installation of the PUREX Surveillance and Monitoring and Control System (SAMCONS) Trailer Uninterruptible Power Supply (UPS) components and wiring will be systematically evaluated by performance of this procedure.

Proper operation of the SAMCONS computer UPS will be verified by performance of a timed functional load test, and verification of associated alarms and "trouble" indications.

This test procedure will be performed in the SAMCONS Trailer and will include verification of receipt of alarms at the SAMCONS computer stations.

This test may be performed at any time after the completion of HNF-SD-CP-ATP-083, "PUREX Surveillance and Monitoring and Control System (SAMCONS) Acceptance Test Procedure", when computer display and alarm functions have been proven to operate correctly.

\subsection{REFERENCES}

2.1 1 Phase PWM Uninterruptible Power Supply System (Stand-Alone) Operating and Maintenance Manual

\subsection{RESPONSIBILITIES}

The following personnel will be required for the performance of this procedure:

- SAMCONS Cognizant Engineer: The individual assigned direct responsibility for the performance, preparation, and adequacy of the test.

- TestDirector: The engineer assigned shift responsibility for performance of the test.

- Test Engineer: The engineer assigned to assist and relieve the Test Director during the performance of the test.

- Field Engineer (Field Personnel): A Test Engineer, Test Director, or Technician, and one or more instrument technicians or electricians, assigned to direct/verify/conduct field testing activities.

Only personnel designated by the SAMCONS Cognizant Engineer are allowed to direct testing per this procedure, and perform equipment operating and control functions.

DOCUMENT NO:

HNE-SD-CP-ATP-091
REVISIONNO:

0 


\section{PUREX (SAMCONS) UPS ACCEPTANCE TEST PROCEDURE}

One engineer acting as either a Test Engineer or as a Test Director is required to be present during testing.

If, during testing, any indicated parameter or control function is not correct or appears to be

malfunctioning, then the engineer conducting this test shall make a determination as to the feasibility of continuing testing. Since actual PUREX UPS operation will occur during this test, there may be a safety impact to continuing the test and completing corrective actions later. A record of all noted deficiencies will be kept on Attachment 1, "Exception List".

At the completion of all testing, approval of all data collected and system performance shall be documented on Attachment 4, "Final Procedure Acceptance Sheet".

Any required changes to this procedure shall be approved by the SAMCONS Cognizant Engineer, or a designated representative, and may be made as "pen-and-ink" changes in all official and working copies of the procedure. An entry shall be made in the official Test Log fully describing the change or changes and the reason for the change(s). An ECN, documenting the change or changes, shall be initiated by the SAMCONS Cognizant Engineer and approved per administrative requirements, however testing is not required to be stopped during the ECN initiation and approval process.

\subsection{DESCRIPTION OF THE SYSTEM}

The PUREX SAMCONS Trailer UPS provides regulated power from an AC power source to the SAMCONS computers during normal system operation and regulated power, for up to two hours, from a dedicated battery bank during loss of the normal AC supply.

The portions of the UPS to be tested include:

- Proper functioning of control panel alarms and "trouble" indications

- Proper functioning of the normal AC power supply

- Proper functioning of the battery back-up power supply for a minimum of two hours

- Proper functioning of alarm displays on the SAMCONS computers

\subsection{TEST CONDITIONS AND EQUIPMENT REQUIRED}

\subsection{Jumpers and Lifted Leads}

In this procedure, there are several occasions when leads are lifted and landed at various terminals. Some of these leads will be energized, and some cabinet internals will be energized to voltages at levels up to $120 \mathrm{Vac}$. Hand and eye protection shall be worn, and insulated tools shall be used, when working on or near energized circuits $(120 \mathrm{Vac})$, if required. The instrument leads and cabinet internals must be energized to verify proper functioning of system equipment and alarms.

\begin{tabular}{|l|c|c|}
\hline $\begin{array}{l}\text { DOCUMENT NO: } \\
\text { HNNF-SD-CP-ATP-091 }\end{array}$ & 0 & PAGE NO: \\
\hline
\end{tabular}




\subsection{Unexpected Alarms}

If unexpected PUREX facility equipment alarms or abnormal indications are received during testing, testing evolutions shall be immediately suspended and actions, as prescribed in approved PUREX facility Alarm Response and Emergency Procedures, shall be taken by responsible PUREX facility personnel to place the equipment/facility in a safe, stable condition. When the reason for the unexpected condition is understood and resolved, then testing activities may be. resumed after permission to do so is received from the SAMCONS Cognizant Engineer.

5.3 Prior to initiation of testing, and at the start of each shift during testing, test personnel shall be briefed on the scope of testing to be conducted during the shift. The briefing shall include any equipment to be operated or controlled during the shift. Additionally, a discussion of work in the facility that could affect testing shall also be held between the SAMCONS Cognizant Engineer and the acting Test Director in charge of the test to be conducted.

5.4 Prior to initiation of testing, the following items shall be verified:

5.4.1 The SAMCONS Trailer UPS is installed, batteries are charged, and the system is ready for testing.

Verified by: $\frac{1}{\text { (Test Director) } \quad \text { Date }}$

5.5 Prior to initiation of testing, the following equipment shall be available for use:

5.5.1 Insulated hand tools normally required for accessing equipment cabinets and terminal boards

5.5.2 Any personnel safety equipment required for performance of work on or near energized equipment $(120 \mathrm{Vac})$.

5.5.3 Stopwatch, commercial accuracy (no calibration required)

5.5.4 One pair of electrical test leads with alligator clips

5.6 Attachment 2, "Measurement and Test Equipment Record Sheet", is included in Section 8.0 for recording data associated with $M \& T E$ used during the performance of this procedure.

DOCUMENT NO:

HNF-SD-CP-ATP-091
REVISIONNO:

0
PAGE NO:

5 OF 13 


\subsection{PROCEDURE}

\subsection{SAMCONS Trailer UPS Testing}

6.1.1 If any discrepancy is noted during testing, then record a description of the condition in Attachment 1.

6.1.1.1 For each discrepancy recorded, enter an identifying number in the "EXCEPTION NUMBER" Column of Attachment 1.

6.1.1.2 Reproduce Attachment 1 as needed, and attach the additional pages to this procedure, to record all discrepancies noted during testing.

6.1.2 Ensure that the UPS batteries are fully charged and ready for testing.

\section{NOTE:}

The "BYPASS TOALT. LINE" switch is located inside of the UPS cabinet.

6.1.3 Ensure that the UPS is on-line and that the "BYPASS TOALT. LINE" switch is in "NORMAL".

\section{NOTE:}

The "RECTIFIER INPUT" and "RECTIFIER OUTPUT" circuit breakers are located on the UPS cabinet door.

6.1.4 Ensure that the "RECTIFIER INPUT" and "RECTIFIER OUTPUT" circuit breakers are closed.

6.1.5 Verify that no UPS "FAULT" alarm LEDs are illuminated on the UPS cabinet.

6.1.6 Display the "Main" screen on either SAMCONS computer station.

6.1.7 Verify that the SAMCONS Skid UPS status is displayed as "OK" in green letters on the SAMCONS computer "Main" screen.

6.1.8 Press and hold the "MAN. TRANSFER TO ALTERNATE" pushbutton on the UPS cabinet and verify that the static switch transfers power to the alternate line.

6.1.9 Release the "MAN. TRANSFER TO ALTERNATE" pushbutton on the UPS cabinet and verify that the static switch transfers power back to the inverter. 


\section{NOTE:}

The four UPS alarm output to SAMCONS relays are located inside the UPS cabinet, on the righthand side cabinet wall, near eye level.

6.1.10 Open the UPS cabinet door and locate the four UPS alarm to SAMCONS output relays.

\section{NOTE:}

Vendor drawing No. 4111-65-79181-00, in Section 4 of the UPS vendor manual, shows the four UPS to SAMCONS output relays and associated terminal strips.

6.1.11 Install a jumper across TB1 terminals 2 and 3 and verify that the "UPS Battery Operation" alarm is received on the SAMCONS computer station.

6.1.12 Verify that the SAMCONS Skid UPS status is displayed as "BAD" in red letters on the SAMCONS computer "Main" screen.

6.1.13 Remove the jumper from TB1 and verify that the "UPS Battery Operation" alarm is clear at the SAMCONS computer station.

6.1.14 Verify that the SAMCONS Skid UPS status is displayed as "OK" in green letters on the SAMCONS computer "Main" screen.

6.1.15 Install a jumper across TB2 terminals 2 and 3 and verify that the "UPS Common Fault" alarm is received on the SAMCONS computer station.

6.1.16 Verify that the SAMCONS Skid UPS status is displayed as "BAD" in red letters on the SAMCONS computer "Main" screen.

6.1.17 Remove the jumper from TB2 and verify that the "UPS Common Fault" alarm is clear at the SAMCONS computer station.

6.1.18 Verify that the SAMCONS Skid UPS status is displayed as "OK" in green letters on the SAMCONS computer "Main" screen.

6.1.19 Install a jumper across TB3 terminals 1 and 2 and verify that the "UPS Static Switch Protection Fail" alarm is received on the SAMCONS computer station.

6.1.20 Verify that the SAMCONS Skid UPS status is displayed as "BAD" in red letters on the SAMCONS computer "Main" screen.

6.1.21 Remove the jumper from TB3 and verify that the "UPS Static Switch Protection Fail" alarm is clear at the SAMCONS computer station.

\begin{tabular}{|l|c|c|}
\hline DOCUMENT NO: & REVISION NO:: & PAGE NO:: \\
HNNF-SD-CP-ATP-091 & 0 & 7 OF 13 \\
\hline
\end{tabular}


6.1.22 Verify that the SAMCONS Skid UPS status is displayed as "OK" in green letters on the SAMCONS computer "Main" screen.

6.1.23 Install a jumper across TB4 terminals 1 and 2 and verify that the "UPS Manual Bypass" alarm is received on the SAMCONS computer station.

6.1.24 Verify that the SAMCONS Skid UPS status is displayed as "BAD" in red letters on the SAMCONS computer "Main" screen.

6.1.25 Remove the jumper from TB4 and verify that the "UPS Manual Bypass" alarm is clear at the SAMCONS computer station.

6.1.26 Verify that the SAMCONS Skid UPS status is displayed as "OK" in green letters on the SAMCONS computer "Main" screen.

6.1.27 Ensure that both SAMCONS Trailer computer stations and all other SAMCONS related equipment in the SAMCONS Trailer is energized and on-line.

6.1.28 Reset the stopwatch.

\section{NOTE:}

The UPS is required to power the SAMCONS for a minimum of two hours.

6.1.29 Close the UPS cabinet door, open the UPS battery charger power supply circuit breaker, and start the stopwatch.

6.1.30 Monitor the SAMCONS while the system is being powered from the UPS battery bank for abnormal operation, and verify that the UPS does not automatically shift to the "Alternate" line.

6.1.31 After two hours has elapsed on the stopwatch, stop the stopwatch and restore the UPS to normal operation per the instructions contained in the vendor manual.

\subsection{TEST DATA SHEETS}

None

\subsection{ATTACHMENTS}

Attachment 1, Exception List

Attachment 2, Measurement and Test Equipment Record Sheet

\begin{tabular}{|l|c|c|}
\hline DOCUMENT NO: & REVISION NO: & PAGE NO: \\
HNNF-SD-CP-ATP-091 & 0 & 8 OF 13 \\
\hline
\end{tabular}




\section{PUREX (SAMCONS) UPS ACCEPTANCE TEST PROCEDURE}

Attachment 3, Lifted/Landed Leads Log Sheet

Attachment 4, Final Procedure Acceptance Sheet

DOCUMENT NO:.

HNF-SD-CP-ATP-091
REVISION NO:

0
PAGE NO:

9 OF 13 


\section{PUREX (SAMCONS) UPS ACCEPTANCE TEST PROCEDURE}

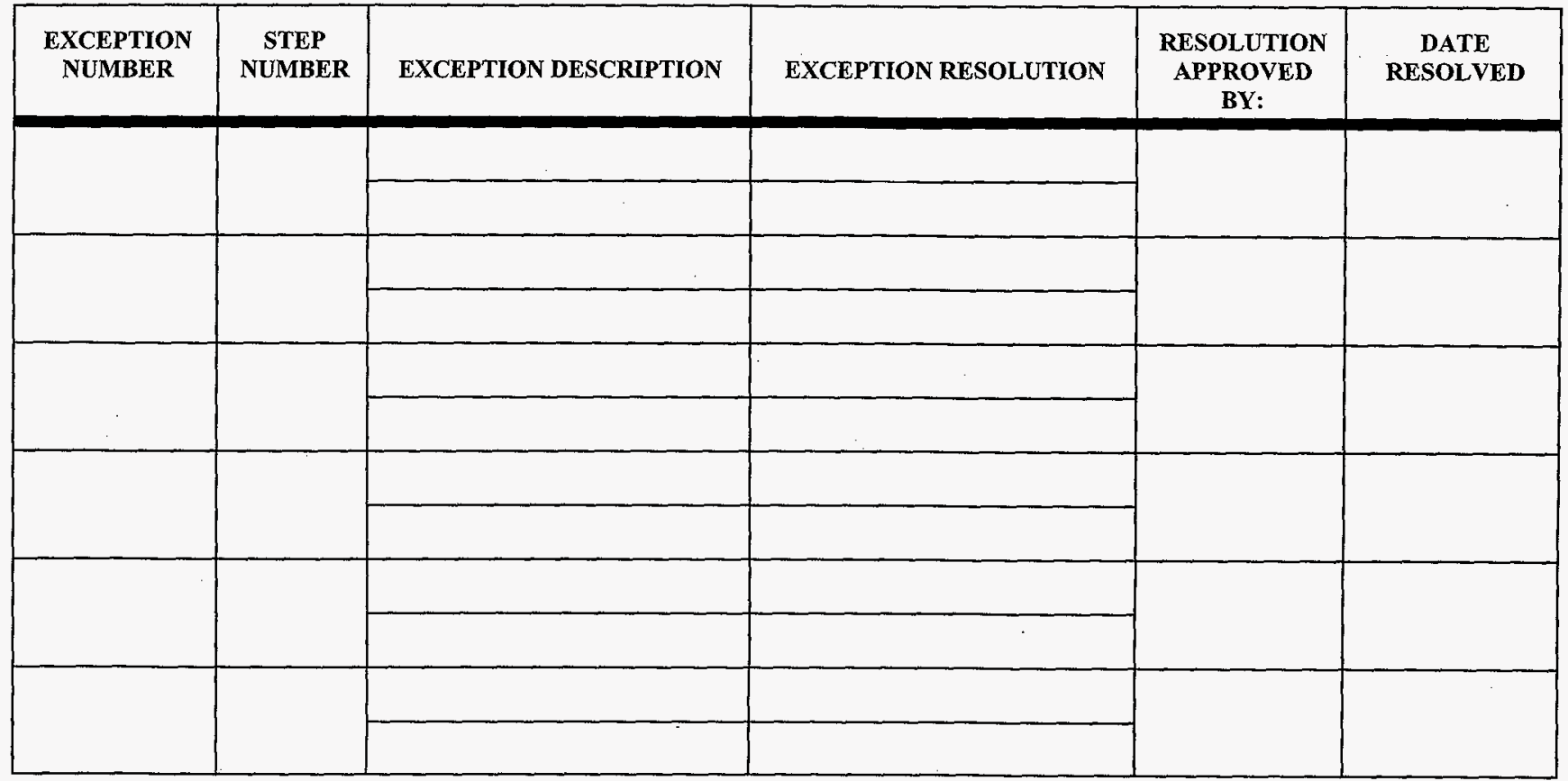

Attachment 1: Exception List 


\section{PUREX (SAMCONS) UPS ACCEPTANCE TEST PROCEDURE}

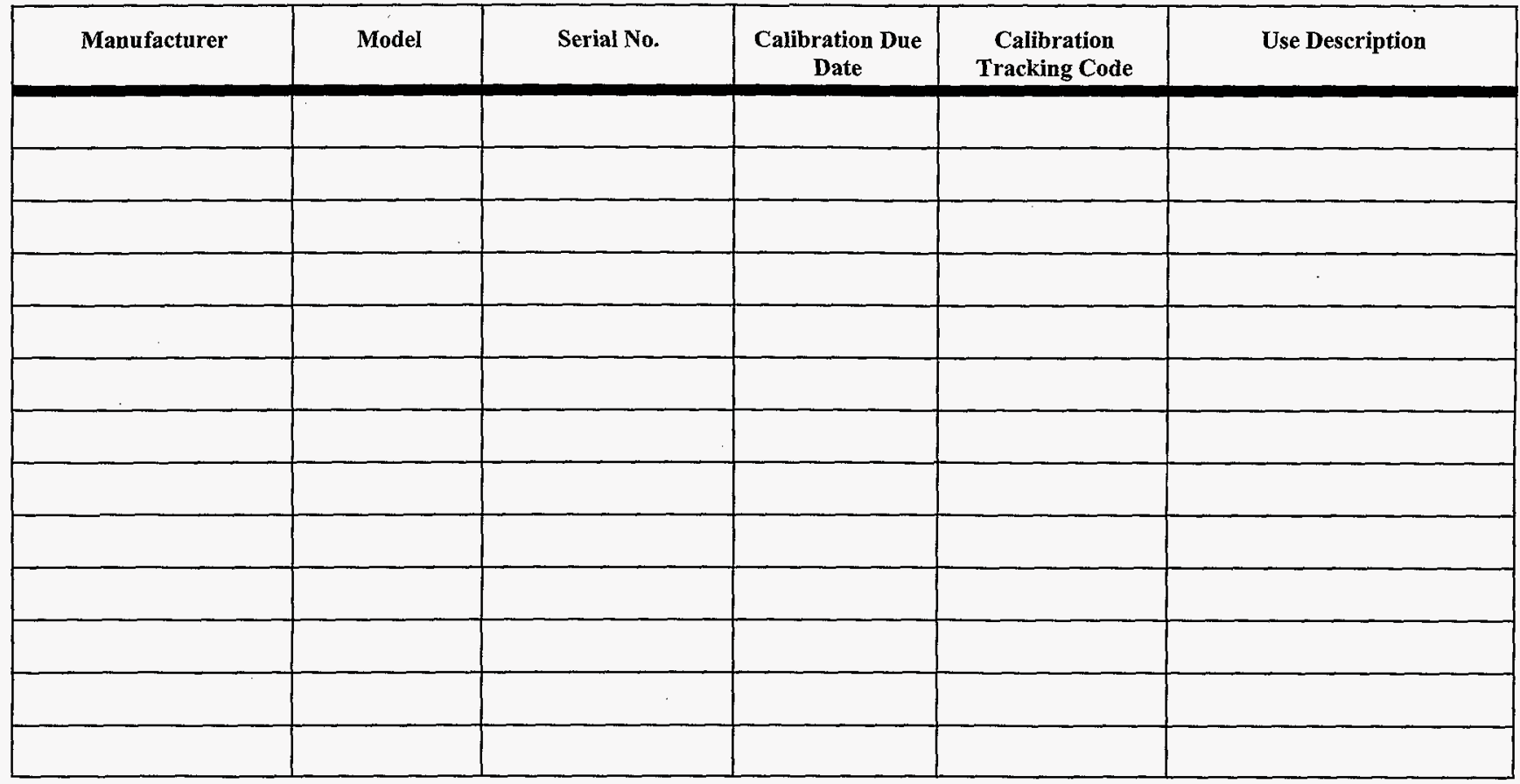

Attachment 2: Measurement and Test Equipment Record Sheet

\begin{tabular}{|l|c|c|}
\hline $\begin{array}{l}\text { DOCUMENT NO:- } \\
\text { HNNF-SD-CP-ATP-091 }\end{array}$ & $\begin{array}{c}\text { REVISION NO:: } \\
0\end{array}$ & 11 OF 13 \\
\hline
\end{tabular}




\section{PUREX (SAMCONS) UPS ACCEPTANCE TEST PROCEDURE}

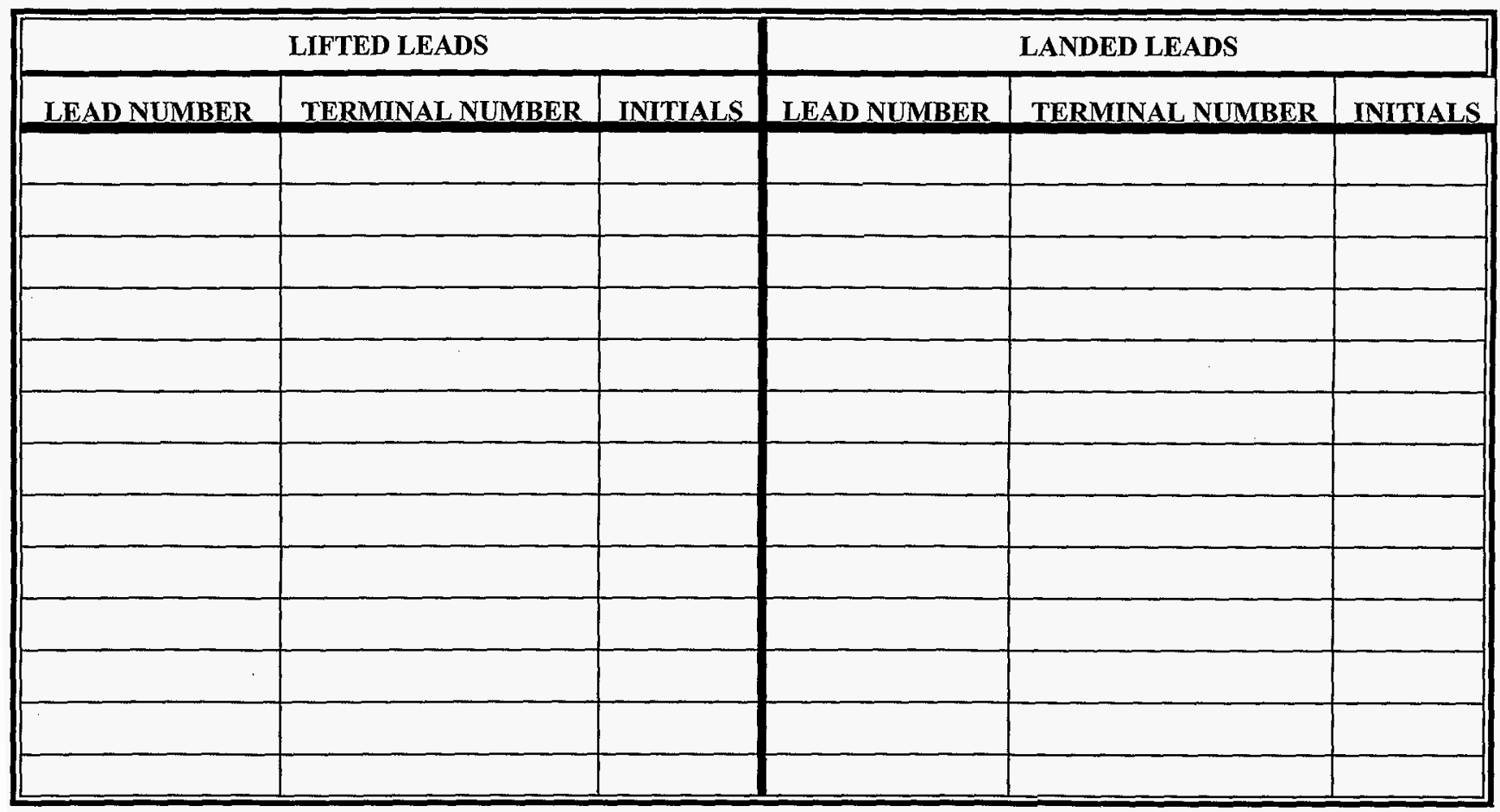

Attachment 3; Lifted/Landed Leads Log Sheet

\begin{tabular}{|l|c|c|}
\hline $\begin{array}{l}\text { DOCUMENT NO: } \\
\text { HNF-SD-CP-ATP-091 }\end{array}$ & 0 & REVISION NO: \\
\hline
\end{tabular}




\section{PUREX (SAMCONS) UPS ACCEPTANCE TEST PROCEDURE}

Completion of this procedure has demonstrated that:

- The SAMCONS Trailer UPS operates to supply regulated AC to the SAMCONS computers, both from the normal AC power supply and from the battery back-up power supply.

- The SAMCONS Trailer UPS will supply power to the SAMCONS computers for a minimum of two hours from the back-up battery supply.

- The SAMCONS Trailer UPS audible and visible alarms and alarm silence functions perform correctly.

- A record of all noted deficiencies was kept on Attachment 1, Exception List, and all recorded exceptions have been resolved and the resolutions approved.

\section{Approved by:}

W. "Bud" Blackaby,

Date

PUREX SAMCONS Cognizant Engineer,

PUREX Stabilization Project

W. A. Peiffer

Date

PUREX Project Activity Manager

R. W. Bailey

Date

PUREX Stabilization Project Manager

Facility Stabilization Project Manager

Attachment 4: Final Procedure Acceptance Sheet

DOCUMENT NO:

HNF-SD-CP-ATP-091
REVISION NO:

0
PAGE NO:

13 OF 13 